\title{
Research gaps for three main tropical diseases in the People's Republic of China
}

\author{
Qi Zheng' ${ }^{1}$, Samantha Vanderslott ${ }^{2}$, Bin Jiang ${ }^{1}$, Li-Li Xu', Cong-Shan Liu', Le-Le Huo ${ }^{1}$, Li-Ping Duan', Ning-Bo Wu', \\ Shi-Zhu Li ${ }^{1}$, Zhi-Gui Xia ${ }^{1}$, Wei-Ping $\mathrm{Wu}^{1}$, Wei Hu${ }^{1}$ and Hao-Bing Zhang ${ }^{1 *}$
}

\begin{abstract}
This scoping review analyzes the research gaps of three diseases: schistosomiasis japonica, malaria and echinococcosis. Based on available data in the P.R. China, we highlight the gaps between control capacity and prevalence levels, and between diagnostic/drug development and population need for treatment at different stages of the national control programme. After reviewing the literature from 848 original studies and consultations with experts in the field, the gaps were identified as follows. Firstly, the malaria research gaps include (i) deficiency of active testing in the public community and no appropriate technique to evaluate elimination, (ii) lack of sensitive diagnostic tools for asymptomatic patients, (iii) lack of safe drugs for mass administration. Secondly, gaps in research of schistosomiasis include (i) incongruent policy in the implementation of integrated control strategy for schistosomiasis, (ii) lack of effective tools for Oncomelania sp. snail control, (iii) lack of a more sensitive and cheaper diagnostic test for large population samples, (iv) lack of new drugs in addition to praziquantel. Thirdly, gaps in research of echinococcosis include (i) low capacity in field epidemiology studies, (ii) lack of sanitation improvement studies in epidemic areas, (iii) lack of a sensitivity test for early diagnosis, (iv) lack of more effective drugs for short-term treatment. We believe these three diseases can eventually be eliminated in mainland China if all the research gaps are abridged in a short period of time.
\end{abstract}

Keywords: Schistosomiasis, Malaria, Echinococcosis, Epidemiology, Diagnosis, Chemotherapy, Research capacity building

\section{Multilingual abstracts}

Please see Additional file 1 for translations of the abstract into the six official working languages of the United Nations.

\section{Background}

Schistosomiasis, malaria and echinococcosis are three types of tropical diseases that threaten more than two billion people worldwide [1-3]. These diseases mostly affect poor rural communities in developing countries [4] and those who are infected with such pathogens not only suffer indisposition but also have various degrees of morbidity, which induce poorer standards of living [5-9].

Continuous economic growth over the last 30 years has allowed the government of the People's Republic of

\footnotetext{
* Correspondence: zhanghaobing@hotmail.com

${ }^{1}$ National Institute of Parasitic Disease, Chinese Center for Disease Control and Prevention, WHO Collaborating Centre on Malaria, Schisostomiasis and Filariasis, Key Laboratory of Parasite and Vector Biology, Ministry of Health, 207 Rui Jin Er Rd, Shanghai 200025, People's Republic of China Full list of author information is available at the end of the article
}

China (P.R. China) to continuously increased its budget for parasitic disease control, resulting in a significant reduction in disease burden and transmission capacity throughout the country [10-12]. Furthermore, an effective national strategy has successfully brought down the prevalence levels of schistosomiasis japonica and malaria compared to levels of 50 years ago [13-15]. Echinococcosis has also been controlled to a stable level according to the fiveyear national surveillance report made by the Ministry of Health $(\mathrm{MOH})$. Such achievements can be attributed to political commitments, control strategies adapted to the national control programme, as well as the innovative research and research capacity building [16].

The major research achievements of last 30 years are reflected in the progress in drug development, evaluation of diagnostics with the national control programme and the formation of a strong team for operational research, providing the required information and tools for the national control programmes. Due to these diseases being at various stages of the national control programme the sensitivity of diagnosis is also different (See Figure 1). It 


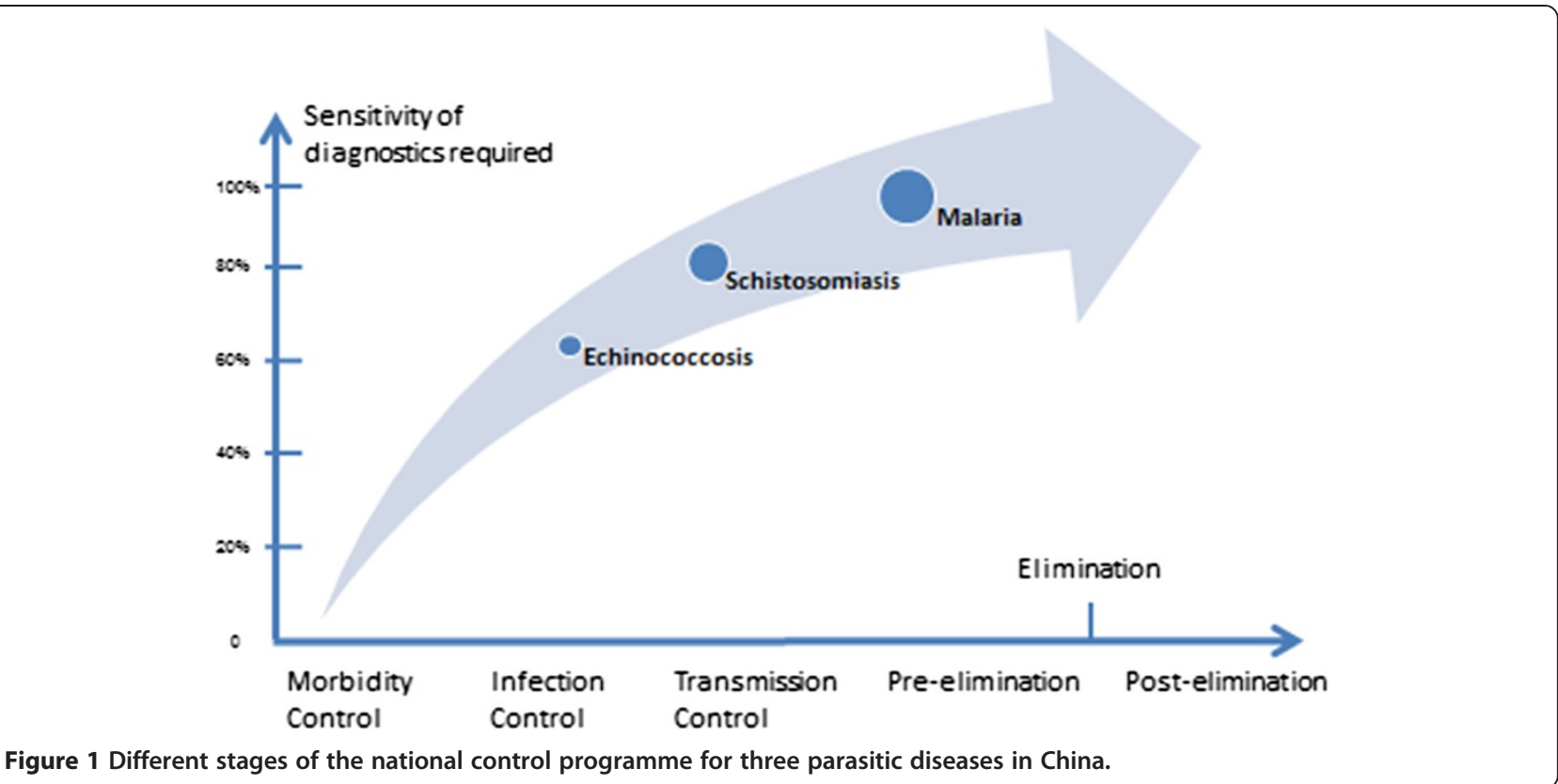

is believed that without advances in operational research, it will be an uphill struggle to reach the aim of elimination for schistosomiasis japonica and malaria in P.R. China. Moreover, without a new strategy and technical support, the currently controlled situation for echinococcosis may worsen.

\section{Review}

The main purpose of this paper is to summarize and disseminate relevant research findings on the three parasitic diseases, so as to identify research gaps in the existing literature. A consultation study was undertaken through the platform of Chinese Network on Drug and Diagnostic Innovation (China NDI, www.chinandi.org.cn) focusing on gaps (i) between research capacity and prevalence, and (ii) between diagnostic/drug R\&D capacity and population need for treatment at different stages of the national control programme.

\section{Methods}

Our scoping review uses an adapted version of the ARKSEY and O'MALLEY (2005) framework [17], involving the following steps:

1. Identification and development of the research questions.

The overarching research questions are as follows: What is the gap between control capacity and prevalence among these three diseases? What is the gap between diagnostic/drug R\&D capacity and population needs for treatment at the different stages of the national control programmes?
2. Location, screening and selection of relevant publications.

Terms were searched for in two most common databases:PubMed database (http://www.pubmed. com) and international articles from Medline database, as well as the Wanfang database (http://www.wanfangdata.com.cn) for Chinese articles. Cqvip database, Cnki database and Wanfang database are the three most popular Chinese periodical databases in China. The percentage of overlap in core journals of these three databases is more than $95 \%$ in the research areas relevant to this scoping review (biotechnology, medicine and health). We selected the Wanfang database after comparing the quality of information by testing key words among three databases mentioned above ${ }^{\mathrm{a}}$.

3. Publication selection The searching procedure yielded 10,835 abstracts. A team constituting of eight professional researchers were responsible for publication selection. Level 1 relevancy testing went as follows:

1) Title, author and abstracts were scanned to determine whether they were relevant with epidemiology, diagnosis and chemotherapy of the three parasitic diseases we focused on in China.

2) The study must have been launched in China and include at least one Chinese author.

After the level 1 relevancy testing, 1677 citations were identified for inclusion in this paper. Full articles were then obtained for level 2 relevancy testing. Team members selected and eliminated 
those publications that focused on single case report or treatment, vaccines, animal models, species validation, surgical treatment and phylogenetic study. Through this filtering, 860 articles were deemed relevant and selected for inclusion. Of these articles, 12 were excluded in data extraction as they could not classified into epidemiology, diagnosis and chemotherapy by their full text. A total of 848 articles were included in this research, with the review process is outlined in Figure 2.

4. Data extraction.

The data extracted was consolidated in a 'data extraction form' using a database programme, which divided the three different diseases along three research fields (epidemiology, diagnosis and chemotherapy). We collated a mixture of general information about the study along with specific information relevant to our research and recorded the information as follows:

- Author(s), year of publication, location and study site(s)

- Intervention type

- Populations

- Aim

- Methodology

- Outcome measures

- Results

This data formed the basis of the analysis. We sought a uniform approach to all 848 studies included in the review. In practice we found out that approximately $8 \%$ of the included articles did not present all the information we needed.

5. Consultation exercise.

As indicated in the background, this scoping study also included a consultation element. Since 2010, more than 300 scholars attended our public meetings to discuss drugs, diagnostics innovation and control for tropical diseases in China. The minutes of these meetings were extracted for gap analysis and considered in comparison to the literature review.

6. Collating, summarizing and reporting the results Once the outlined steps were completed, we were able to present our narrative account of findings. Particular attention was given to a basic numerical analysis of the studies included in the review. Since there was great diversity and/or overlaps among reports, we rejected much of the very detailed information in order to make the table clearer. We hope these tables can present readers with an intuitive impression of the three diseases in China. In addition the team evaluated the full text of each paper and supplementary information was collated in the corresponding summary table.

\section{Result}

Gaps between research capacity and disease prevalence After we extracted and analyzed the chosen articles, the relevant data was collected and summarized for thematic findings from the full text of the articles (Table 1).

\section{Malaria}

Prevalence In 2011, there were 4479 malaria cases reported through the infectious diseases reporting system from 782 counties of 27 Provinces in P.R. China (total 2856 counties of 31 provinces). $68.9 \%$ of the reported cases were in Yunnan, Anhui, Jiangsu, Henan and Sichuan provinces [18].

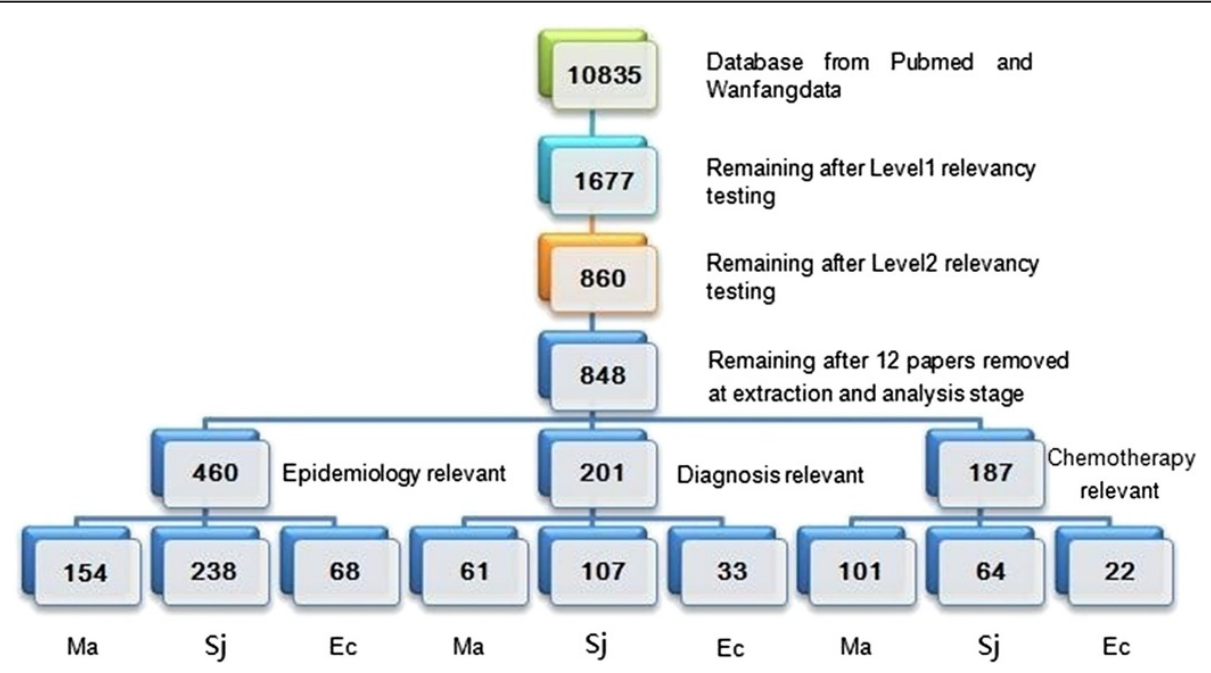

Figure 2 Results of the search strategy. (Abbreviation: Ma instead for Malaria; Sj instead for Schistosomiasis japonica; Ec instead for Echinococcosis). 
Table 1 Prevalence data collected from relevant articles for three main parasitic diseases in China

\begin{tabular}{|c|c|c|c|c|c|c|c|c|c|c|}
\hline \multirow[b]{2}{*}{ Disease (n) } & & \multirow{2}{*}{$\begin{array}{l}\text { Count of } \\
\text { articles }\end{array}$} & \multicolumn{5}{|c|}{ Survey population range } & \multicolumn{3}{|c|}{ Epidemic data } \\
\hline & & & $0 \sim 1 \mathrm{~K}(\%)$ & $1 \mathrm{~K} \sim 10 \mathrm{~K}(\%)$ & $10 \mathrm{~K} \sim 100 \mathrm{~K}(\%)$ & $100 \mathrm{~K} \sim 1 \mathrm{M}(\%)$ & $1 \mathrm{M} \sim 10 \mathrm{M}(\%)$ & $\begin{array}{c}\text { Survey } \\
\text { population }\end{array}$ & $\begin{array}{c}\text { Positive serology } \\
\text { rate }\end{array}$ & $\begin{array}{l}\text { Average } \\
\text { morbidity }\end{array}$ \\
\hline \multirow{3}{*}{ Malaria (154) } & Survey for humans & 154 & $13(15.1 \%)$ & $27(31.4 \%)$ & $24(27.9 \%)$ & $21(24.4)$ & $1(1.1 \%)$ & 110958 & $0.06 \%$ & $0.00062 \%(0-0.2 \%)$ \\
\hline & Survey for mosquito & 6 & 0 & $2(33.3 \%)$ & $2(33.3 \%)$ & $2(33.3 \%)$ & 0 & 72776 & - & $0.009 \%$ \\
\hline & $\begin{array}{l}\text { Survey for animal } \\
\text { (definitive host) }\end{array}$ & 1 & $1(100 \%)$ & 0 & 0 & 0 & 0 & 328 & $3.4 \%$ & - \\
\hline \multirow{3}{*}{ Schistosomisis (238) } & Survey for human & 238 & $53(22.2 \%)$ & $86(36.1 \%)$ & $61(25.6 \%)$ & $33(13.8 \%)$ & $5(2.1 \%)$ & 192061 & $14.2 \%(0-60.1 \%)$ & $3.5 \%(0-17.9 \%)$ \\
\hline & $\begin{array}{l}\text { Survey for Oncomelania } \\
\text { hupensis }\end{array}$ & 61 & $9(14.7 \%)$ & $18(29.51 \%)$ & $18(29.51 \%)$ & $13(21.3 \%)$ & $3(4.9 \%)$ & 57251 & - & $0.26 \%(0-1.2 \%)$ \\
\hline & $\begin{array}{l}\text { Survey for animal } \\
\text { (definitive host) }\end{array}$ & 75 & $23(30.6 \%)$ & $26(34.6 \%)$ & $18(24.0 \%)$ & $8(10.6 \%)$ & $0(0.0 \%)$ & 49773 & - & $3.81 \%(0-28.5 \%)$ \\
\hline \multirow{3}{*}{ Echinococcosis (68) } & Survey for human & 68 & $21(30.9 \%)$ & $41(60.3 \%)$ & $6(8.8 \%)$ & 0 & 0 & 6022 & $20.8 \%(8.9-55.2 \%)$ & $7.40 \%(0.15 \%-29.3 \%)$ \\
\hline & $\begin{array}{l}\text { Survey for pika, mice, } \\
\text { livestock }\end{array}$ & 40 & $21(62.5 \%)$ & $13(35.0 \%)$ & $1(2.5 \%)$ & 0 & 0 & 4016 & - & $24.9 \%(2.4 \%-54.9 \%)$ \\
\hline & $\begin{array}{l}\text { Survey for animal } \\
\text { (definitive host) }\end{array}$ & 18 & $14(77.8 \%)$ & $3(16.7 \%)$ & $1(5.5 \%)$ & 0 & 0 & 1609 & $39.2 \%(12.6-83.0 \%)$ & $26.5 \%(1.0-70.4 \%)$ \\
\hline
\end{tabular}


According to the Chinese Health Statistical Digest published by the Ministry of Health of P.R. China, the number of total malaria cases reported has declined significantly over the past ten years (Figure 3). Yet imported malaria cases began to dominate and became prevalent throughout the country after almost two years [19]. The imported malaria cases accounted for $66.4 \%$ of total malaria cases in 2011.

Gaps in eliminating malaria When the goal for the national malaria control programme changes from control to elimination, the strategy on target population and control methods will need to be revised accordingly [20,21]. There are two gaps identified in eliminating malaria.

Gap 1: Lack of active surveillance in the public communities.

In the pre-elimination control stage, malaria carriers may be the main source of infection in the remaining epidemic area [22,23]. According to this research, only $5 \%$ malaria articles are relevant to active surveillance in the epidemic area. This condition was also identified from the national survey of malaria in 2010. In that year, the population tested for malaria in fever clinics was 7.1 million, while the field site survey population was only 0.14 million. Therefore, we recommend that more active surveillance activities be put in place to diagnose malaria carriers in suspicious residual epidemic sites in the future.

Gap 2: There is no appropriate technique to effectively evaluate elimination.

When indigenous malaria cases decreased sharply, the proportion of imported cases of falciparum malaria accounted that for all malaria cases increased from $1.5 \%$ in 2003 to $31.6 \%$ in 2011[10,18,24-29]. However, there are still no

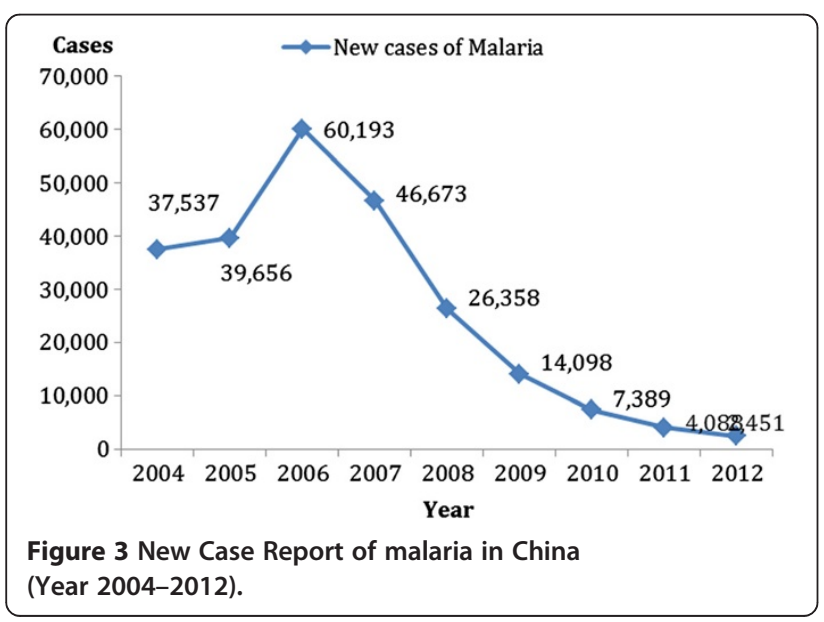

articles relevant to the technique that can accurately distinguish imported cases from local cases [30]; this has also led to the problem of judging between new cases and recurring cases. In the later stage of malaria elimination, it is difficult to evaluate whether an area has really eliminated malaria or not. Thus, effective biomarkers urgently need to be developed in order to distinguish imported cases from local cases.

\section{Schistosomiasis japonica}

Prevalence In China, schistosomiasis japonica was epidemic throughout 12 provinces after liberation in the 1950s. By 1995 five provinces had blocked the transmission of Schistosoma japonicum [31]. However, transmissions still occurred in provinces along the Yangtze River and its southern areas in 2010, particularly in Hunan, Hubei, Jiangxi, Anhui and Jiangsu, and in the mountainous and hilly regions of Sichuan and Yunnan provinces. From 2004 to 2012, the number of acute cases of schistosomiasis japonica reported has dramatically declined from 816 to 13 [32-39] (Figure 4). However, there are still approximately 68 million individuals at risk [39]. In this study, 238 articles were judged relevant to epidemiology of S. japonicum in China. In Table 1, the average number of each survey article for human, Oncomelania sp snail and definitive host in animals are respectively 192061, 57251 and 49773. In these articles, most of the studies are reported from the 12 provinces mentioned above. To support the large amount of surveillance work that is needed to collect this information, China has thousands of professional staff responsible for the supervision and control of schistosomiasis japonica. For Hunan province, the Hunan Institute of Parasitic Diseases (HIPD) is an important guarantor of schistosomiasis control work throughout the province. The institute has over 400

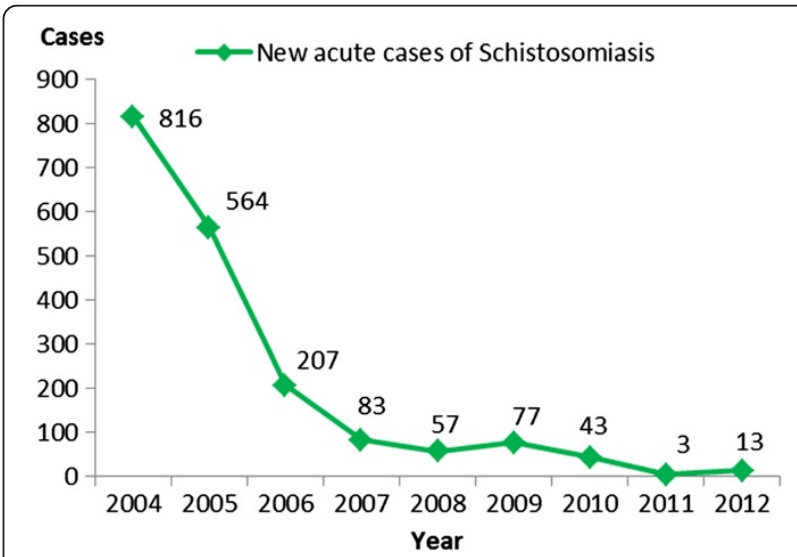

Figure 4 The number of acute cases of schistosomiasis japonica in China (Year 2004-2012). 
professional staff and a hospital equipped with 300 beds for treating patients with schistosomiasis [40].

\section{Gaps in controlling schistosomiasis japonica}

Gap 1: Present policy cannot completely ensure the execution of an integrated intervention strategy for schistosomiasis control.

In China the national control programmes for schistosomiasis japonica is now at the transmission control stage. The goal at present is to decrease the schistosomiasis infection rate to $1 \%$ by 2015 . Chinese authorities have also discussed the possibility of achieving elimination of schistosomiasis japonica by the year 2020. To realize these goals, a fourpronged approach has been investigated since 2008 [41,42]. The objective of the approach is to interrupt the environmental contamination of schistosome eggs as follows: First, replace buffaloes with tractors. Second, restrict marshland used for pasturing and encourage fenced cattle-farming. Third, improve sanitation facilities in houses. Fourth and last, provide toilets for mobile populations (e.g. fishermen). In general, the integrated measures for schistosomiasis japonica control with an emphasis on controlling the sources of infection have had strong effects [43-45]. However, in some less developed areas particularly regions retaining traditional customs of using buffaloes for farming considerable resistance has been faced for implementation because the strategy is contrary to the interests of the local economy [46-48]. Some marshland is still contaminated by infected cattle and many residents are under threat of schistosomiasis japonica [29].

Gap 2: Lack of effective tools for Oncomelania sp. snail control.

The habitat environment of the Oncomelania sp. snail in China has seen no significant change during the last 5 years $[38,49,50]$. Oncomelania sp. snails can proliferate in many kinds of habitat. In 2010, the total habitat area with snails was about 1608.7 million $\mathrm{M}^{2}$, presenting an ambitious task for elimination by manpower [51]. Three factors boost the expansion of the infected Oncomelania sp. snail's habitats. 1) Unpredictable flooding of the Yangtze River. 2) More than 40 species of mammals that can act as reservoir hosts. 3) Millions of migrating people including patients moving to non-endemic rural areas. Such trends may threaten those non-endemic areas [52-56]. For this reason, the control of schistosomiasis japonica is not steady and can easily see repeated outbreaks. A new Oncomelania sp. snail control technique should be developed, for example, to find its natural predator or develop a biotechnological method to induce infecundity [57].

\section{Echinococcosis}

Prevalence In China, new cases of echinococcosis have been increasing continuously since 2004 (Figure 5). The population at risk is approximately 66 million. The national survey of important parasitic diseases in 2004 showed that the average prevalence rate for populations in endemic areas was 1.08\% [58]. From 2004 to 2008, 27 provinces out of 31 had reported cases of echinococcosis and $98.2 \%$ of the reported cases were in Inner Mongolia, Tibet, Gansu, Qinghai, Ningxia, Xinjiang and Sichuan province [58].

Echinococcosis is also a kind of zoonosis [59]. According to the "Prevention and treatment of echinococcosis Action Plan (2010-2015)", the number of infected livestock in P. R. China amounts to about 50 million every year. Thus echinococcosis is one of the main reasons leading a large amount of herdsmen to poverty [60].

\section{Gaps in control of echinococcosis}

Gap 1: Low capacity for controlling echinococcosis According to Chinese echinococcosis control policy, it is important to treat each dog in epidemic areas every month to control the main infection source $[61,62]$. The strategy is actually relatively straightforward, but the execution is very hard considering the enormous amount of dogs in these pasturing areas, which cover $40 \%$ of land in P.R. China [63-65]. In addition, most of the residents in

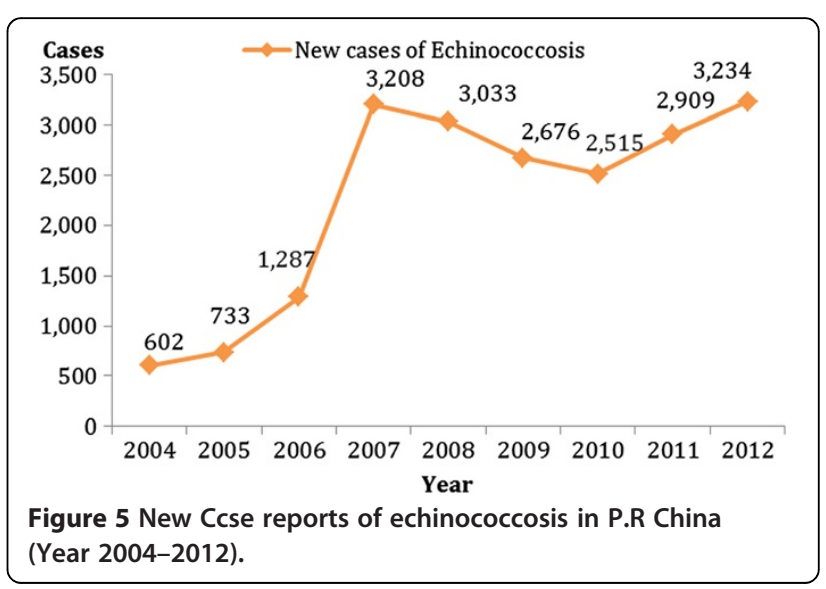


these areas lack the corresponding prevention knowledge and are reluctant to change their living habits, such as feeding flesh viscera of sheep to dogs and touching dog fur [66-69].

Gap 2: Manpower restrictions in field survey. According to the studies of echinococcosis in relevant papers, the total and average survey population $(6,022)$ is far less than for the other two diseases (192,061 and 110,958). A low population density in epidemic areas, along with manpower restrictions are the main reasons for this situation occurring. It is imperative to train a larger number of echinococcosis researchers and improve their remuneration for these epidemic areas.

Gap 3: Not enough support for hygiene and sanitation in high transmission areas.

In high-transmission regions, the hygiene and sanitation conditions are usually unsatisfactory [70,71]. Most of these areas lack access to tap water; households collect water several times a day from contaminated lakes or rivers for personal use and drinking without boiling [72,73]. In addition the limited supply of water is not sufficient enough for washing hands [72,73]. These risk factors are hard to change for certain living environments and industries, especially in poor domestic economic situations.

\section{Gaps between diagnostic/drug development and population need for treatment}

Relevant data has been collected and summarized to find the research gaps in diagnostic/drug development in the three diseases (Tables 2 and 3).

\section{Gaps in diagnostic development}

Gap 1: Lack of malaria sensitive diagnostic tools for asymptomatic patients and patients at low levels of parasitemia.

There were 61 papers that introduced the diagnosis of malaria. The availability of rapid diagnostic tests has made it possible to improve and expand diagnostic testing for malaria. In field surveys, PCR and LAMP diagnostic tools have the highest sensitivity (96.1-99.6\%) and specificity $(98.8-100 \%)$, but high cost and new technical requirements are obstacles for wider use [74]. GICA as a diagnostic tool appears to be the popular area in research and development as it is easy to use and has a lower cost, but the level of sensitivity is not satisfactory (88\%-95\%). We concluded from

Table 2 Diagnosis data collected from relevant articles for three main parasitic diseases in China

\begin{tabular}{|c|c|c|c|c|c|c|c|c|c|c|c|}
\hline \multirow{2}{*}{$\begin{array}{l}\text { Disease } \\
\text { Disease }\end{array}$} & \multirow[b]{2}{*}{ Total } & \multicolumn{4}{|c|}{$\begin{array}{l}\text { Immunodiagnosis method Research in field } \\
\text { survey }\end{array}$} & \multicolumn{6}{|c|}{ Development of immunodiagnosis kit } \\
\hline & & Type (n) & Sensitivity & Specificity & Population & $\overline{\text { Total }}$ & $\begin{array}{l}\text { Leading research } \\
\text { direction }\end{array}$ & Labwork & $\begin{array}{l}\text { Human } \\
\text { test }(n)\end{array}$ & $\begin{array}{c}\text { Basic } \\
\text { Science }\end{array}$ & $\overline{\text { Marketization }}$ \\
\hline \multirow{4}{*}{ Malaria } & \multirow[t]{4}{*}{$26^{*}$} & $\mathrm{GlCA}(9)$ & $88.4-95.5 \%$ & $95.7-100 \%$ & 547 & \multirow[t]{4}{*}{35} & \multirow[t]{4}{*}{ GICA (9) } & \multirow[t]{4}{*}{16} & \multirow[t]{4}{*}{19} & \multirow[t]{4}{*}{$11 / 35$} & \multirow[t]{4}{*}{$24 / 35$} \\
\hline & & ICA(14) & $74.2-98.6 \%$ & $91.3-100 \%$ & 938 & & & & & & \\
\hline & & $\mathrm{PCR}(10)$ & $96.1-99.6 \%$ & $98.8-100 \%$ & 167 & & & & & & \\
\hline & & $\operatorname{LAMP}(2)$ & $98.3-98.8 \%$ & $100 \%$ & 46 & & & & & & \\
\hline \multirow{7}{*}{ Schistosomiasis } & \multirow[t]{7}{*}{$55^{*}$} & СOPT(3) & $90.0-91.8 \%$ & $95.3-97.4 \%$ & 89 & \multirow[t]{7}{*}{52} & \multirow{7}{*}{$\begin{array}{c}\text { Candidate } \\
\text { Recombination } \\
\text { Protein Finding (28) }\end{array}$} & \multirow[t]{7}{*}{41} & \multirow[t]{7}{*}{11} & \multirow[t]{7}{*}{$44 / 52$} & \multirow[t]{7}{*}{$8 / 52$} \\
\hline & & $\mathrm{DDIA}(8)$ & $75.3-97.1 \%$ & $55.1-99.0 \%$ & 755 & & & & & & \\
\hline & & DIGFA(9) & $92.0-100 \%$ & $92.2-97.5 \%$ & 556 & & & & & & \\
\hline & & ELISA(25) & $65.8-98.4 \%$ & $51.7-100 \%$ & 716 & & & & & & \\
\hline & & $\operatorname{IHA}(32)$ & $69.6-97.3 \%$ & $63.6-97.8 \%$ & 743 & & & & & & \\
\hline & & $\operatorname{PCR}(4)$ & $100 \%$ & $100 \%$ & 52 & & & & & & \\
\hline & & Others(6) & $85.5-98.5 \%$ & $76.3-97.0 \%$ & 85 & & & & & & \\
\hline \multirow{4}{*}{ Echinococcosis } & \multirow[t]{4}{*}{$9^{*}$} & $\| \mathrm{HA}(4)$ & $87.1-92.7 \%$ & $69.5-91.6 \%$ & 315 & \multirow[t]{4}{*}{24} & \multirow[t]{4}{*}{ DIGFA (6) } & \multirow[t]{4}{*}{8} & \multirow[t]{4}{*}{16} & \multirow[t]{4}{*}{$5 / 24$} & \multirow[t]{4}{*}{$19 / 24$} \\
\hline & & DIGFA(2) & $56.7-93.2 \%$ & $79.1-95.0 \%$ & 180 & & & & & & \\
\hline & & ELISA(8) & $59.3 \%-91.2 \%$ & $93.8-100 \%$ & 289 & & & & & & \\
\hline & & Others(3) & $32.5 \%-76.9 \%$ & $41.3-81.6 \%$ & 42 & & & & & & \\
\hline
\end{tabular}

Note: *More than one diagnosis method was used in one article.

Abbreviation: COPT Circum oval precipitating test, DDIA Dipstick dye immuno-assay, DIGFA Dot immunogold filtration assay, ELISA Enzyme-linked immunosorbent Assay, IHA Indirect hemagglutination assay, ELIB Enzyme-linked immuno-electrotransfer blot, ICA immunochromatographic, GICA Gold immunochromatography assay, LAMP Loop-medicated isothermal amplification. 
Table 3 Chemotherapy data collected from relevant articles for three main parasitic diseases in China

\begin{tabular}{|c|c|c|c|c|c|c|c|c|}
\hline \multirow{2}{*}{ Disease } & \multirow{2}{*}{ Article (n) } & \multicolumn{3}{|c|}{ Clinical trial for $\mathrm{MOH}$ Recommended drug } & \multicolumn{4}{|c|}{ Drug development } \\
\hline & & Drug's name $(\mathrm{n})$ & Cure rates (\%) & Population & Labwork (n) & Clinical trial (n) & Basic science & Marketization \\
\hline \multirow{7}{*}{ Malaria } & \multirow{7}{*}{$51^{*}$} & Dihydroartemisinin (31) & $70 \%-100 \%$ & \multirow{7}{*}{$104(15-1205)$} & \multirow[t]{7}{*}{50} & \multirow[t]{7}{*}{0} & \multirow[t]{7}{*}{$50 / 50$} & \multirow[t]{7}{*}{$0 / 50$} \\
\hline & & Artemether (30) & $79.8 \%-100 \%$ & & & & & \\
\hline & & Piperaquine (19) & $80 \%-100 \%$ & & & & & \\
\hline & & Artesunate (18) & $90.7 \%-100 \%$ & & & & & \\
\hline & & Chloroquine (9) & $62.8 \%-100 \%$ & & & & & \\
\hline & & Primaquine (9) & $85.5 \%-100 \%$ & & & & & \\
\hline & & $\begin{array}{l}\text { Artemether- } \\
\text { lumefantrine (1) }\end{array}$ & $82.50 \%$ & & & & & \\
\hline Schistosomiasis & 22 & Praziquantel (22) & $74.7 \%-100 \%$ & $221(33-615)$ & 42 & 0 & $42 / 42$ & $0 / 42$ \\
\hline \multirow{2}{*}{ Echinococcosis } & \multirow{2}{*}{$11^{*}$} & Albendazole emulsion (7) & $57.1 \%-83.1 \%$ & $95(36-264)$ & \multirow[t]{2}{*}{11} & \multirow[t]{2}{*}{9} & \multirow[t]{2}{*}{$11 / 20$} & \multirow[t]{2}{*}{$9 / 20$} \\
\hline & & Albendazole tablet (6) & $15.8 \%-31.3 \%$ & 57 (24-108) & & & & \\
\hline
\end{tabular}

* More than one kind of drug can be studied in one article.

articles that in China over $90 \%$ of cases are tested by blood smears. This indicates that the diagnostic kit currently available on the market has not met the requirements of epidemic areas. A new diagnosis kit is needed for $P$. vivax with two components during pre-elimination stage. Firstly, it should have a high accuracy for low parasitemia density patients (both sensitivity and specificity should more than 95\%). Secondly, it needs to detect G6PD deficiency (Glucose-6-phosphate dehydrogenase deficiency) because antimalarial drugs as primaquine, pamaquine, and chloroquine can cause acute haemolysis in people with G6PD deficiency [75].

Gap 2: Lack of a more sensitive and cheaper diagnostic test for S. japonicum infection of large population samples.

There were 107 papers introducing the diagnosis of schistosomiasis japonica. ELISA and IHA are the most common methods used on field sites. However, DIGFA has proved to have better sensitivity and accuracy. Therefore it is anticipated to be the future candidate used in large-scale surveys. In the research and development area, researchers focus on candidate-finding in recombination protein. This tendency is supported by the achievement of whole-genome sequencing of S. japonicum in China.

More than $80 \%$ of field surveys in China use immunodiagnostic kits combined with faecal examination. Antibody detection is very useful in screening for large-scale endemic surveys, in order to quickly acquire the baseline infection rate of schistosomiasis japonica. Faecal examination is recommended for determining the character that antibodies persist after parasitological cure. Moreover, microscopy may also miss infections, especially for those who are only moderately infected and in areas of low transmission [76-78]. Since an enormous amount of samples are to be identified for schistosomiasis elimination in the near future, the ideal diagnosis method should be more sensitive and significantly cheaper than any of the presently available methods.

Gap 3: Lack of sensitive test for early diagnosis of echinococcosis.

In China, ultrasonography is the most frequently used test for echinococcosis diagnosis $[79,80]$. Immunodiagnostic tests are also widely used in fieldwork. The kits used most widely are the ELISA-based serological tests, using either an Echinococcus granulosus hydatid cyst fluid antigen or an E. multilocularis crude vesicular fluid for primary screening. The sensitivity for hepatic cases of CE (Cystic echinococcosis) ranges from $85 \%$ to $98 \%$. For AE (Alveolar echinococcosis), the use of purified or recombinant E. multilocularis antigens exhibit high diagnostic sensitivities ranging from between $91 \%$ and $100 \%$, with overall specificities of $98 \%-100 \%$ [81]. However, for echinococcosis formed in other organs except for liver, the specificities are less than $50 \%$. DIGFA seems to be the current area of interest for research and development.

In general, more imaging procedures should be used in echinococcosis epidemic areas to diagnose patients. For Immunodiagnostic tests, the gap is to develop new serological tests with higher sensitivity and specificity (>95\%) than 
those based on the use of hydatid fluid and then bring them to a world standard. The resulting drug should also be straightforward and cheap to produce, with the capacity to diagnose early stage echinococcosis and allow for early treatment.

\section{Gaps in drug development}

Gap 1: Lack of safe drugs for both mass production and active again hypnozoites of $P$. vivax. Antimalarial drugs are essential in moving from control to elimination [82]. A 8-day therapeutic schedule by using chloroquine plus primaquine for $P$. vivax has now replaced the old schedule for 21-days and 14-days in China. The patient cure rates for 8-days chemotherapy is $96.9 \%$ $100 \%$. Also an artemisinin-based combination therapy is widely used in China to treat $P$. Falciparum with cure rate of $82.4 \%-100 \%$. Still, no new drug has been successfully developed in the past 10 years in China.

P.vivax was detected in more than $99 \%$ of local malaria cases diagnosed microscopically. A characteristic of $P$. vivax infections is relapses originating from hypnozoites. There is a need for a radical cure to abate the source of infection during the course of malaria elimination [83]. New drugs are to be developed for hypnozoites and should be safe for patients with G6PD deficiency.

Gap 2: The public needs a new drug for prophylactic treatment of schistosomiasis.

Praziquantel is the sole drug for treatment and morbidity control of schistosomiasis japonica. Praziquantel is safe, cheap and effective against adult worms. In China, cure rates of up to 8595.3\% have been achieved but complete cures (100\%) are seldom. Praziquantel does not prevent reinfection because it's effects only last a few hours and it cannot kill immature worms [84]. Artemether was proved to kill immature worms over the first 21 days post inoculation in laboratory [85,86], yet there has been no further research to support its application and dissemination in large-scale chemotherapy combined with praziquantel for antischistosoma japonicum.

Many animal experiments have been conducted using mefloquine for antischistosomiasis [87-89]. The results indicate that mefloquine exhibits an extensive and severe damage both to juvenile and adult $S$. japonicum harbored in mice. Nevertheless, this is still a long way from field application when there is a public need also for a new drug in addition to praziquantel. Firstly, the new drug is required to be cheap, safe and effective

Table 4 Gaps of control capacity and diagnostic/drug development presented in total 4 consultation meetings

\begin{tabular}{|c|c|c|}
\hline Diseases & No. & Gap from consultation \\
\hline \multirow[t]{6}{*}{ Malaria } & 1 & Need new diagnosis method for asymptomatic patients \\
\hline & 2 & Need innovative and safer drugs \\
\hline & 3 & Lack of techniques to distinguish abroad-imported cases from indigenous cases \\
\hline & 4 & Difficulty in finding asymptomatic patients \\
\hline & 5 & Need new surveillance system for pre-elimination period \\
\hline & 6 & More focus on the continuously increasing imported cases \\
\hline \multirow[t]{6}{*}{ Schistosomiasis japonica } & 1 & Need higher sensitive antigen testing \\
\hline & 2 & Need new drug which can prevent reinfection \\
\hline & 3 & Need new molluscicide with less negative impact on the environment and biodiversity \\
\hline & 4 & Difficulty in testing for a moving population \\
\hline & 5 & Need innovative surveillance-response approaches system \\
\hline & 6 & Difficulty in controlling for more than 40 hosts \\
\hline \multirow[t]{6}{*}{ Echinococcosis } & 1 & Need effective drug for short-term treatment \\
\hline & 2 & Need financial support for hygiene and sanitation in epidemic areas \\
\hline & 3 & Need long-acting antihelmintic implants or drugs to control dog infection \\
\hline & 4 & Need effective vaccine for people in epidemic areas \\
\hline & 5 & Need more sensitive serological test for field survey \\
\hline & 6 & Control of the wildlife transmission cycles of $\mathrm{E}$ multilocularis is difficult \\
\hline
\end{tabular}


so that it can be used for mass drug administration. Secondly, it should not produce the cross-resistance with praziquantel. Thirdly, it will preferably be effective against both juvenile and adult worms.

Gap 3: Lack of a more effective drug for a short-term treatment of echinococcosis. In China, more than $94 \%$ echinococcosis patients were treated by chemotherapy, with only $6 \%$ of patients requiring an operation. Changing the dosage forms of albendazole tablets is the main achievement in echinococcosis chemotherapy in China [90,91]. Both albendazole emulsion and liposomal albendazole have proved more effective than albendazole tablet for E. granulosus [92-94]. However, there are shortages in the current chemotherapy approach as it is a long course of treatment (at least 3 months lifelong) and has relative low cure rates (8.2\%-74.5\%) [94-96]. An adverse effect rate of more than $20 \%$ is another main reason for patients to give up their medicine course $[97,98]$. Therefore, a new more efficient drug urgently needs to be developed.

\section{Gaps identified by consultations}

The minutes of four consultation meetings were extracted into a list of the most important gaps presented by experts. This list in addition to the full text of included articles provides further detail to our study (See Table 4).

\section{Discussion}

The choice of scoping framework in the article through gap identification is based on our previous experience of

Table 5 Recommendations for overcome gaps of control capacity and diagnostic/drug development reported in this article

\begin{tabular}{|c|c|c|c|}
\hline Diseases & Research area of gaps & Specific gaps & Recommendation for overcome gaps \\
\hline \multirow[t]{4}{*}{ Malaria } & \multirow[t]{2}{*}{ Epidemic control } & $\begin{array}{l}\text { Need more active surveillance for } \\
\text { early detection }\end{array}$ & $\begin{array}{l}\text { More precise prediction by statistical model and geographical } \\
\text { information systems (GIS). Set up active surveillance and } \\
\text { response system to prevent reestablishment of transmission. }\end{array}$ \\
\hline & & $\begin{array}{l}\text { No appropriate techniques to evaluate } \\
\text { elimination }\end{array}$ & $\begin{array}{l}\text { Set up clonal germplasm repository for plasmodium and its } \\
\text { vectors. Find specific biomarker to distinguish different } \\
\text { geographic strain. }\end{array}$ \\
\hline & Diagnosis & $\begin{array}{l}\text { Need new diagnosis method for } \\
\text { asymptomatic patient }\end{array}$ & $\begin{array}{l}\text { Find new candidate biomarkers. Quality sampling for diagnostic } \\
\text { kits before large-scale testing in field. }\end{array}$ \\
\hline & Chemotherapy & Need innovative and safer drugs & $\begin{array}{l}\text { Accelerate the validation and standardization for candidate drugs. } \\
\text { Strengthen international cooperation in new drug development. }\end{array}$ \\
\hline \multirow[t]{4}{*}{$\begin{array}{l}\text { Schistosomiasis } \\
\text { japonica }\end{array}$} & \multirow[t]{2}{*}{ Epidemic control } & $\begin{array}{l}\text { Need effective tools for Oncomelania sp. } \\
\text { snail control }\end{array}$ & $\begin{array}{l}\text { Develop diagnostic assays for the large-scale screening of } \\
\text { specific snails. Use GIS for prediction of snail distribution. } \\
\text { Develop new snail interventions. }\end{array}$ \\
\hline & & $\begin{array}{l}\text { Need policy support to protect the } \\
\text { execution of control strategy }\end{array}$ & $\begin{array}{l}\text { Coordinate by local government. Give full administration } \\
\text { enforcement rights to the Chinese Center for Disease Control } \\
\text { and Prevention. }\end{array}$ \\
\hline & Diagnosis & $\begin{array}{l}\text { Need more sensitive and cheaper } \\
\text { diagnostic test for large population } \\
\text { sampling. }\end{array}$ & $\begin{array}{l}\text { Find new candidate biomarkers. Focus on innovation of } \\
\text { immune complex dissociation procedure to increase the } \\
\text { sensitivity of detection. }\end{array}$ \\
\hline & Chemotherapy & $\begin{array}{l}\text { Need new drugs in addition to } \\
\text { praziquantel. }\end{array}$ & $\begin{array}{l}\text { Accelerate the validation and standardization for candidate drugs. } \\
\text { Strengthen international cooperation in new drug development. }\end{array}$ \\
\hline \multirow[t]{5}{*}{ Echinococcosis } & \multirow[t]{3}{*}{ Epidemic control } & $\begin{array}{l}\text { The execution for control echinococcosis } \\
\text { is not satisfying. }\end{array}$ & $\begin{array}{l}\text { Coordinate by local government. Give proper administration } \\
\text { enforcement right to the Chinese Center for Disease Control } \\
\text { and Prevention. }\end{array}$ \\
\hline & & $\begin{array}{l}\text { Manpower restrictions in echinococcosis } \\
\text { control }\end{array}$ & $\begin{array}{l}\text { Larger personnel force for echinococcosis control. More } \\
\text { professional training for echinococcosis control. }\end{array}$ \\
\hline & & $\begin{array}{l}\text { Not enough support for hygiene and } \\
\text { sanitation in epidemic areas. }\end{array}$ & $\begin{array}{l}\text { Government increase in financial support on hygiene and } \\
\text { sanitation improvement in these areas. Strengthen health } \\
\text { education on echinococcosis prevention. }\end{array}$ \\
\hline & Diagnosis & $\begin{array}{l}\text { Need more sensitive test for early } \\
\text { diagnosis }\end{array}$ & $\begin{array}{l}\text { Undertake a comparative study of all the available antibody } \\
\text { detection to form guidelines for large-scale scanning. Find new } \\
\text { candidate biomarkers. }\end{array}$ \\
\hline & Chemotherapy & $\begin{array}{l}\text { Need more effective drug for short-term } \\
\text { treatment }\end{array}$ & $\begin{array}{l}\text { Accelerate the validation and standardization for candidate } \\
\text { drugs. Focus to develop new form of benzimidazole to } \\
\text { improve its bioavailability. Strengthen international cooperation } \\
\text { in new drug development. }\end{array}$ \\
\hline
\end{tabular}


scoping studies. The scoping review has centered on the identification and development of key research questions. The questions concern location, screening and selection of relevant publications; publication selection; data extraction; collating, summarizing and reporting the results. The resulting research gaps reported in our study also relied on two main sources. First, the literature review from which we extracted the papers to use and then summarized information from selected papers. Second, the gaps extracted in consultation. Overall we have identified, summarized and reported on about 13 research gaps in this paper. Experts in this study then gave corresponding advice on how to overcome gaps (See Table 5).

In this research, we endorse a consultation element to enhance a scoping review study. Choosing this route can enhance the veracity of final gap analysis and also ensure that the results more practically applicable. For instance, in the consultation meetings, experts presented the idea that P.R China needed a new technique to evaluate malaria elimination. Since P. R. China announced the objective to eliminate malaria only two years ago, few papers mentioned this gap. If we used a traditional systematic review, we may have not identified more immediate and forward-looking research gaps. Although such an element may be considered an 'optional extra' for scoping review, the consultation exercise did indeed provide 'added value' to the literature review. The limit of this research is in the deficiency of vaccine analysis. We do not have any professional team members working on the vaccine area. Our concern was in giving a fair evaluation on the part of vaccine research and therefore we have not incorporated vaccine research into the theme of the study.

When comparing the research priorities among the three diseases, malaria, schistosomiasis and echinococcosis, in aspects of diagnostics and drugs the major difference was found in two areas. One is the requirements of sensitivity and specificity in diagnosis, and the other is effectiveness of drug treatment, due to the different stage of the diseases control programme. For instance, for the preelimination stage of malaria, higher sensitivity and specificity diagnostics is needed both in individual and in population diagnosis [99]. At the same time, the tools used in the certification of malaria elimination, also needs to be further developed [100]. This is a concern as to the fact that innovative drugs or drug combinations are given a higher priority to reduce the risk of drug resistance $[101,102]$. For the transmission control stage of schistosomiasis, it is necessary for high sensitivity tools to screen the at risk population, in order to guide the MDA or selective chemotherapy based on different endemicity levels and further reduce transmission risks $[5,77,78]$. New drugs need to be developed for prophylactic treatment to effectively for target all stages of the parasites [2]. For the morbidity or infection control stage of echinococcosis, it is necessary to develop the early diagnostics, for individual and population uses [103]. Effective drugs with a shorttime chemotherapy also requires development [3]. Both early diagnostics and short-time schemes for the effective treatment will contribute significantly to the reduce burden of disease [104]. Therefore, this comparative approach provides a clear indication of the diagnostic drugs that are necessary to be used in the different stages of the control programme.

The major problem has been that investment into the national control or elimination programmes has fallen after the burden of disease. We suggest that sustained investment in the development of diagnostics and drugs is required. This needs to be well budgeted for at all stages, with the argument put to policy makers that a marginal effect applies in the different stages of the national control programme, whether it be from morbidity or infection control to elimination.

\section{Conclusions}

Today, although some areas of research on schistosomiasis japonica, malaria and echinococcosis have been neglected, they are now attracting high levels of concern from many nations, including P.R China. The government is providing sustained financial and technical support underpinned by key control targets. Thus we believe these three diseases can eventually be controlled or eliminated in mainland China following years of sustained efforts.

\section{Endnote}

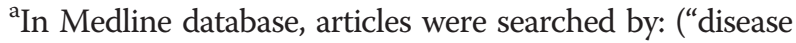
name"[MeSH Terms] OR "disease name”[All Fields]) AND ("china" [MeSH Terms] OR "china"[All Fields]) AND (“2007/06/05”[PDat]: “2012/06/05”[PDat] AND English [lang]). In Chinese Wanfangdata, articles were searched by ("disease name"[MeSH Terms] or "disease name "[All Fields]) and ("therapy" [MeSH Terms] or "treatment" or "drug-resistance" [MeSH Terms] or "adverse event" [MeSH Terms] or "diagnosis" [MeSH Terms] or "examination" or "test" or "epidemiology" [MeSH Terms] or "survey" or "surveillance" or "investigation" or "monitoring from June 2007 to June 2012.

\section{Additional file}

Additional file 1: Multilingual abstracts in the six official working languages of the United Nations.

\section{Competing interests}

The authors declare that they have no conflicting interests.

\section{Authors' contributions}

QZ conceived the study, carried out data collection and analysis and drafted the manuscript. HBZ conceived the project and revised the manuscript. SV 
revised the manuscript and provided intellectual input to the interpretation of the findings. BJ, LLX, CSL, LLH, LPD and NBW conceived the project and carried out data collection and analysis. SZL, ZGX, WPW, WH conceived the project and revised the manuscript. HBZ mainly conceived the project and revised the manuscript. All authors read and approved the final manuscript.

\section{Acknowledgments}

This work was supported by UNICEF/UNDP/World Bank/WHO Special Programme on Research and Training in Tropical Diseases (No. 70350) through China NDI Initiative (Chinese Network on Drug and Diagnostic Innovation) and by Chinese National Science and Technology Major Project (No. 2008ZX10004-11, 2012ZX10004-220) and the Special Foundation for Technology Research of Science and Technology Research Institute from the Ministry of Science and Technology of China(No.2011EG150312). We are indebted to the participants of the First and Second Workshop of China NID. We are indebted to Dr. Charles Ezeh of the University of Nigeria who helped with revising the grammar in this article.

\section{Author details}

${ }^{1}$ National Institute of Parasitic Disease, Chinese Center for Disease Control and Prevention, WHO Collaborating Centre on Malaria, Schisostomiasis and Filariasis, Key Laboratory of Parasite and Vector Biology, Ministry of Health, 207 Rui Jin Er Rd, Shanghai 200025, People's Republic of China. ${ }^{2}$ The Department of Science and Technology Studies, University College London, London WC1E 6BT, UK

Received: 28 May 2013 Accepted: 12 July 2013

Published: 29 July 2013

\section{References}

1. Feachem RG, Phillips AA, Hwang J, Cotter C, Wielgosz B, Greenwood BM, Sabot O, Rodriguez MH, Abeyasinghe RR, Ghebreyesus TA, et al: Shrinking the malaria map: progress and prospects. Lancet 2010, 376(9752):1566-1578.

2. Rollinson D, Knopp S, Levitz S, Stothard JR, Tchuente LA, Garba A, Mohammed KA, Schur N, Person B, Colley DG, et al: Time to set the agenda for schistosomiasis elimination. Acta Trop 2012. http://dx.doi.org/ 10.1016/j.actatropica.2012.04.013.

3. Schantz PM: Progress in diagnosis, treatment and elimination of echinococcosis and cysticercosis. Parasitol Int 2006, 55(Suppl):S7-S13.

4. Zhou XN: Prioritizing research for "One health-One world". Inf Dis Poverty 2012, 1(1):1.

5. Bergquist $\mathrm{R}$, Whittaker $\mathrm{M}$ : Control of neglected tropical diseases in the Asia Pacific region: implications for health information priorities. Inf Dis Poverty 2012, 1(1):4.

6. O'Meara WP, Mangeni JN, Steketee R, Greenwood B: Changes in the burden of malaria in sub-Saharan Africa. Lancet Infect Dis 2010, 10(8):545-555.

7. Torgerson PR, Macpherson CN: The socioeconomic burden of parasitic zoonoses: global trends. Vet Parasitol 2011, 182(1):79-95.

8. Boatin BA, Basanez MG, Prichard RK, Awadzi K, Barakat RM, Garcia HH, Gazzinelli A, Grant WN, McCarthy JS, N'Goran EK, et al: A research agenda for helminth diseases of humans: towards control and elimination. PLOS Neglect Trop Dis 2012, 6(4):e1547.

9. Jia TW, Utzinger J, Deng Y, Yang K, Li YY, Zhu JH, King CH, Zhou XN: Quantifying quality of life and disability of patients with advanced schistosomiasis japonica. PLoS Neglect Trop Dis 2011, 5(2):e966.

10. Zhou SS, Wang Y, Fang W, Tang LH: [Malaria situation in the People's Republic of China in 2008]. Zhongguo Ji Sheng Chong Xue Yu Ji Sheng Chong Bing Za Zhi 2009, 27(6):457. 455-456.

11. Wang $L$, Utzinger J, Zhou XN: Schistosomiasis control: experiences and lessons from China. Lancet 2008, 372(9652):1793-1795.

12. Zhang W, Zhang Z, Yimit T, Shi B, Aili H, Tulson G, You H, Li J, Gray DJ, McManus DP, et al: A pilot study for control of hyperendemic cystic hydatid disease in China. PLoS Negl Trop Dis 2009, 3(10):e534.

13. Tambo E, Adebowale AA, Huang F, Chen JH, Zhou SS, Tang LH: Moving malaria from epidemic towards elimination: a tale of events between 1960 and 2012 in Sub Sahara Africa and China. Inf Dis Poverty 2012, 1(1):6.

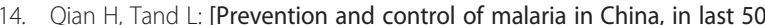
years]. Zhonghua Liu Xing Bing Xue Za Zhi 2000, 21(3):225-227.

15. Wang LD, Guo JG, Wu XH, Chen HG, Wang TP, Zhu SP, Zhang ZH, Steinmann P, Yang GJ, Wang SP, et al: China's new strategy to block
Schistosoma japonicum transmission: experiences and impact beyond schistosomiasis. TMIH 2009, 14(12):1475-1483.

16. So $A D$, Ruiz-Esparza Q: Technology innovation for infectious diseases in the developing world. Inf Dis Poverty 2012, 1(1):2.

17. Arksey H, O'Malley L: Scoping studies: towards a methodological framework. Int J Soc Res Methodol 2005, 8(1):19-32

18. Xia ZG, Yang MN, Zhou SS: [Malaria situation in the People's Republic of China in 2011]. Zhongguo Ji Sheng Chong Xue Yu Ji Sheng Chong Bing Za Zhi 2011, 30(6):419-422.

19. Bi Y, Hu W, Yang H, Zhou XN, Yu W, Guo Y, Tong S: Spatial patterns of malaria reported deaths in Yunnan Province, China. Am J Trop Med Hygiene 2013, 88(3):526-535.

20. Breman JG, Brandling-Bennett AD: The challenge of malaria eradication in the twenty-first century: research linked to operations is the key. Vaccine 2011, 29(Suppl 4):D97-103.

21. Liu J, Yang B, Cheung W, Yang GJ: Modelling malaria diffusion patterns: a network perspective. Inf Dis Poverty 2012, 1(1):11.

22. Liao GLHC, Li SB, Li SY, He DB, Li ZH, SHI XY, Liu M: Elderly long-term relapse of vivax malaria Clinical features and prevention. World Health Digest 2012, 9(4):46-48

23. Yuan FYCG, Zuo SL, Huang GQ: Analysis of the relapse of plasmodium vivax malaria in Hubei (2003-2005). J Public Health Prevent Med 2006, 17(5):39-40.

24. Zhou SS, Tang LH, Sheng HF: [Malaria situation in the People's Republic of China in 2003]. Zhongguo Ji Sheng Chong Xue Yu Ji Sheng Chong Bing Za Zhi 2003, 23(6):385-387.

25. Zhou SS, Tang LH, Sheng HF: Malaria situation in the People's Republic of China in 2004. Zhongguo Ji Sheng Chong Xue Yu Ji Sheng Chong Bing Za Zhi 2006, 24(1):3.

26. Zhou SS, Wang Y, Tang LH: Malaria situation in the People's Republic of China in 2005. Zhongguo Ji Sheng Chong Xue Yu Ji Sheng Chong Bing Za Zhi 2005, 24(6):401-403.

27. Zhou SS, Wang Y, Tang LH: [Malaria situation in the People's Republic of China in 2006]. Zhongguo Ji Sheng Chong Xue Yu Ji Sheng Chong Bing Za Zhi 2006, 25(6):439-441.

28. Zhou SS, Wang Y, Fang W, Tang LH: [Malaria situation in the People's Republic of China in 2006]. Zhongguo Ji Sheng Chong Xue Yu Ji Sheng Chong Bing Za Zhi 2007, 26(6):401-403.

29. Zhou SS, Wang Y, Xia ZG: [Malaria situation in the People's Republic of China in 2006]. Zhongguo Ji Sheng Chong Xue Yu Ji Sheng Chong Bing Za Zhi 2009, 29(1):1-3.

30. Han HGR: Clinical manifestation of 28 infused malarial patients. Anhui Med Pharm J 2011, 15(1):78-79.

31. Zhou XN, Wang LY, Chen MG, Wang TP, Guo JG, Wu XH, Jiang QW, Zheng J, Chen $X Y$ : An economic evaluation of the national schistosomiasis control programme in China from 1992 to 2000. Acta Trop 2005, 96(2-3):255-265.

32. Hao $Y$, Wu XH, Xia G, Zheng H, Guo JG, Wang LY, Zhou XN: [Schistosomiasis status in People's Republic of China in 2004]. Zhongguo xue xi chong bing fang zhi za zhi 2004, 17(6):401-404.

33. Hao $Y$, Wu XH, Xia G, Zheng $H$, Guo JG, Wang LY, Zhou XN: [Schistosomiasis status in People's Republic of China in 2004]. Zhongguo xue xi chong bing fang zhi za zhi 2005, 18(5):321-323.

34. Hao Y, Wu XH, Zheng H, Wang LY, Guo JG, Xia G, Chen Z, Zhou XN: [Schistosomiasis status in People's Republic of China in 2004]. Zhongguo xue xi chong bing fang zhi za zhi 2006, 19(6):401-404.

35. Hao Y, Wu XH, Zheng H, Wang LY, Guo JG, Xia G, Chen Z, Zhou XN: [Schistosomiasis status in People's Republic of China in 2004]. Zhongguo xue xi chong bing fang zhi za zhi 2007, 20(6):401-404

36. Hao Y, Zheng H, Zhu R, Guo JG, Wu XH, Wang LY, Chen Z, Zhou XN [Schistosomiasis status in People's Republic of China in 2008]. Chin J Schistosomiasis Control 2009, 6:451-456. 21.

37. Hao Y, Zheng H, Zhu R, Guo JG, Wang LY, Chen Z, Zhou XN: [Schistosomiasis status in People's Republic of China in 2004] Zhongguo xue xi chong bing fang zhi za zhi 2009, 22(6):521-527.

38. Lei ZL, Zheng H, Zhang LJ, Zhu R, Guo JG, Li SZ, Wang LY, Chen Z, Zhou XN: [Schistosomiasis status in People's Republic of China in 2004]. Zhongguo xue xi chong bing fang zhi za zhi 2010, 23(6):599-604.

39. Zheng H, Zhang LJ, Zhu R, Xu J, Li SZ, Guo JG, Xiao N, Zhou XN: [Schistosomiasis status in People's Republic of China in 2004] Zhongguo xue xi chong bing fang zhi za zhi 2011, 24(6):621-626. 
40. McManus DP, Gray DJ, Ross AG, Williams GM, He HB, Li YS: Schistosomiasis research in the dongting lake region and its impact on local and national treatment and control in China. PLOS Neglect Trop Dis 2011, 5(8):e1053.

41. Wang LD, Chen HG, Guo JG, Zeng XJ, Hong XL, Xiong JJ, Wu XH, Wang XH, Wang LY, Xia G, et al: A strategy to control transmission of Schistosoma japonicum in China. N England J Med 2009, 360(2):121-128.

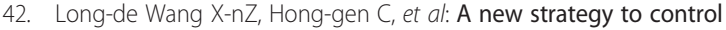
transmission of Schistosoma japonicum. Engineer Sci 2009, 11(5):37-42.

43. He L-C, Wang J-S, Rong X-B, Peng X-W, Zheng-Yin F, He Z-W, Huang W-J, Zhang H-M, Liu J, Peng Y-X: Effect of comprehensive schistosomiasis control strategies with emphasis on infection source control in marshland and lake regions. Chin J Schisto Control 2010, 22(3):278-280.

44. Cao ZG, Wang TP, He JC, Zhang SQ, Chen GX, Zhang GH, Wang H, He ZG: [Evaluation on the effect of comprehensive control strategy of schistosomiasis with emphasis on infection source control in Anhui province]. Zhonghua yu fang yi xue za zhi 2012, 46(2):114-118.

45. Chen H-G, Zeng X-J, Xiong J-J, Jiang W-S, Hong X-L, Shen-Zhu H, Jia-Gang G: Study on comprehensive schistosomiasis control strategy with emphasis on infectious source control in Poyang Lake areas. Chin J Schistosomiasis Control 2009, 21(4):243-249.

46. Seto EY, Remais JV, Carlton EJ, Wang S, Liang S, Brindley PJ, Qiu D, Spear RC, Wang LD, Wang TP, et al: Toward sustainable and comprehensive control of schistosomiasis in China: lessons from Sichuan. PLoS Neglect Trop Dis 2011, 5(10):e1372

47. Yi D-H, Yi P, Liu Z-C, Li Y-S, Quan M-Z, Xiao S-Y: Practice and thought of schistosomiasis control with an emphasis on control sources of infection in Dongting Lake area. Chin J Schisto Control 2009, 21(3):161-164.

48. Liang $X-Y$, Wang $N-R$, Yuan $X-B$ : The problem that faced by schistosomiasis control with an emphasis on control sources of infection and its countermeasure. Yangtze River 2009, 40(3):107-108.

49. Su ZM, He H, Tu ZW, Fan HP, Mao GX, Cao MM, Gao H: [Surveillance of schistosomiasis in Hubei Province in 2010]. Zhongguo xue xi chong bing fang zhi za zhi 2010, 23(4):438-440.

50. Yang H, Xiao-Hua W, Zheng H, Wang L-Y, Guo J-G, Xia G, Chen Z, Zhou X-N: Schistosomiasis situation in People's Republic of China in 2007. Chin J Schisto Conlrol 2008, 20(6):401-404.

51. Collins C, Xu J, Tang S: Schistosomiasis control and the health system in China. Inf Dis Poverty 2012, 1(1):7.

52. Huang SY, Deng ZH, Zhang QM, Lin RX, Zhang XC, Huo LC, Wang JL, Ruan CW: Endemic situation of schistosomiasis in Guangdong Province from 2004 to 2009. Zhongguo xue xi chong bing fang zhi za zhi 2011, 23(2):197-198. 201.

53. Li L, Zhang J-F, Yan X-L, Zhu M-D, Lin L-J, Li-Ling Y, Chen W, Wen L-Y: Epidemiological analysis of epidemic status of schistosomiasis in Zhejiang Province in 2008. Acta Parasitol Med Entomol Sin 2010, 17(2):123-125.

54. Zhou XN, Cai L, Zhang XP, Sheng HF, Ma XB, Jin YJ, Wu XH, Wang XH, Wang LY, Lin T, et al: [Potential risks for transmission of schistosomiasis caused by mobile population in Shanghai]. Zhongguo ji sheng chong xue yu ji sheng chong bing za zhi 2007, 25(3):180-184.

55. Xiaonong Z, Minggang C, McManus D, Bergquist R: Schistosomiasis control in the 21st century. Proceedings of the International Symposium on Schistosomiasis, Shanghai, July 4-6, 2001. Acta tropica 2002, 82(2):95-114.

56. Sleigh A, Jackson S, Li X, Huang K: Eradication of schistosomiasis in Guangxi, China. Part 2: political economy, management strategy and costs, 1953-92. Bull World Health Org 1998, 76(5):497-508.

57. Ding ZJ, Peng GY: [Discussion of schistosomiasis infection source control]. Zhongguo xue xi chong bing fang zhi za zhi 2012, 24(1):117-118.

58. Coordinating Office of the National Survey on the Important Human, et al: [A national survey on current status of the important parasitic diseases in human population]. Zhongguo ji sheng chong xue yu ji sheng chong bing za zhi 2005, 23(5 Suppl):332-340.

59. Euzeby J: Larval echinococcosis, a major zoonosis. Epidemiologic, etiologic and prophylactic study. Maroc medical 1968, 48(518):643-660

60. Prevention and treatment action plan of echinococcosis in year 2010-2015 (Chinese). http://www.moh.gov.cn/cmsresources/mohjbyfkzj/ cmsrsdocument/doc10787.doc

61. Bo Tao BZ, Bao-biao DU: Epidemiological investigation and control effect of echinococcosis in Inner Mongolia autonomous region. Chin J Zoonoses 2011, 27(7):677-678

62. Bin Zhang $X L$, Zhuangzhi S, Song $H$ : A survey on epidemic status of human echinococcusis in Inner Mongolia. Med Ani Prev 2007, 23(12):883-885.
63. Ju Yang TL: Research progress in Hydatid disease epidemiology. Ningxia Med J 2008, 30(4):378-379.

64. Nuerguli Ayimuhan AZ, Buerliesi S: Epidemic investigation of hydatid disease in Toli county. Xinjiang Province Chin Foreign Med Res 2010, 8(9):109-110.

65. Qing Fu XH, Li-ying W, Wei-ping WU: Investigation on epidemic status of echinococcosis in villages of Chengduo county. Qinghai Chin Epidemiol 2010, 31(4):471-472.

66. $Y u$-xiao Huang $Y L$, Junchuan $L$, Zhong-xiong $L$ : Hydatid infection situationof shanxi province and the surrounding area. J Fourth Military Med Univ 2008, 29(5).

67. Cairan D: Epidemic and infection survey on echinococcosis. China Animal Husbandry Vet Med 2008, 35(7):101-102.

68. Malike Zulihumaer N, Chun-hua LV: Wali: investigation of Echinococcus infection in domestic animials in Xinjing. Chin J Vet Parasitol 2011, 19(3):58-59.

69. Su X: Investigation of echinococcosis in population of Go luo state. Sci Technol Info 2011, 19(1):161-162.

70. Ju Y, Li L, Tian-Xi L, Zong-Ren L, Xing-Lin W: Study on prevention knowledge and related behavior of hydatid disease in rural area residents in Xiji county. J Ningxia Med Coll 2008, 30(1):60-62.

71. Pleydell DR, Yang YR, Danson FM, Raoul F, Craig PS, McManus DP, Vuitton DA, Wang Q, Giraudoux P: Landscape composition and spatial prediction of alveolar echinococcosis in southern Ningxia, China. PLoS Neglect Trop Dis 2008, 2(9):e287.

72. Ito A, Urbani C, Jiamin Q, Vuitton DA, Dongchuan Q, Heath DD, Craig PS, Zheng F, Schantz PM: Control of echinococcosis and cysticercosis: a public health challenge to international cooperation in China. Acta tropica 2003, 86(1):3-17.

73. Xiang-Lin W, Min Z, Li L, Yun-Ling F, Ju Y, Ming-Xian D: Hydatid disease risk factor analysis of the human the rural area of Ningxia. Chin J Med Guide 2010, 12(10):1763-1764

74. Hui Xia Y-Z, Shen QG, Fang Q: Field evaluation for malaria surveillance using a plasmodium vivax PCR detection. Chin J Parasitic Dis Control 2000, 13(4):247-249

75. Janney SK, Joist JJ, Fitch CD: Excess release of ferriheme in G6PD-deficient erythrocytes: possible cause of hemolysis and resistance to malaria. Blood 1986, 67(2):331-333.

76. Zhou XN, Bergquist R, Leonardo L, Yang GJ, Yang K, Sudomo M, Olveda R: Schistosomiasis japonica control and research needs. Advances Parasitol 2010, 72:145-178.

77. Zhou XN, Xu J, Chen HG, Wang TP, Huang XB, Lin DD, Wang QZ, Tang L, Guo JG, Wu XH, et al: Tools to support policy decisions related to treatment strategies and surveillance of Schistosomiasis japonica towards elimination. PLoS Neglect Trop Dis 2011, 5(12):e1408.

78. Spear RC, Seto EY, Carlton EJ, Liang S, Remais JV, Zhong B, Qiu D: The challenge of effective surveillance in moving from low transmission to elimination of schistosomiasis in China. Int J Parasito/ 2011, 41(12):1243-1247.

79. Li T, Chen X, Zhen R, Qiu J, Qiu D, Xiao N, Ito A, Wang H, Giraudoux P, Sako $Y$, et al: Widespread co-endemicity of human cystic and alveolar echinococcosis on the eastern Tibetan Plateau, northwest Sichuan/ southeast Qinghai, China. Acta tropica 2010, 113(3):248-256.

80. Jiang CP, Don M, Jones M: Liver alveolar echinococcosis in China: clinical aspect with relative basic research. WJG 2005, 11(30):4611-4617.

81. Xiao N, Mamuti W, Yamasaki H, Sako Y, Nakao M, Nakaya K, Gottstein B, Schantz PM, Lightowlers MW, Craig PS, et al: Evaluation of use of recombinant Em18 and affinity-purified Em18 for serological differentiation of alveolar echinococcosis from cystic echinococcosis and other parasitic infections. J Clin Microbiol 2003, 41(7):3351-3353.

82. Singh N: A new global malaria eradication strategy: implications for malaria research from an Indian perspective. Transact Royal Soc Trop Med Hygiene 2009, 103(12):1202-1203.

83. Adak T, Valecha N, Sharma VP: Plasmodium vivax polymorphism in a clinical drug trial. Clin Diagnostic Lab Immunol 2001, 8(5):891-894.

84. Sabah AA, Fletcher C, Webbe G, Doenhoff MJ: Schistosoma mansoni: chemotherapy of infections of different ages. Exp Parasitol 1986, 61(3):294-303.

85. Xiao S, Tanner M, N'Goran EK, Utzinger J, Chollet J, Bergquist R, Chen M, Zheng J: Recent investigations of artemether, a novel agent for the prevention of schistosomiasis japonica, mansoni and haematobia. Acta tropica 2002, 82(2):175-181.

86. Utzinger J, Xiao S, N'Goran EK, Bergquist R, Tanner M: The potential of artemether for the control of schistosomiasis. Int J Parasitol 2001, 31(14):1549-1562. 
87. Xiao SH, Chollet J, Utzinger J, Mei JY, Jiao PY, Keiser J, Tanner M: Effect of single-dose oral mefloquine on the morphology of adult Schistosoma japonicum in mice. Parasitol Res 2009, 105(3):853-861.

88. Xiao SH, Mei JY, Jiao PY: Effect of mefloquine administered orally at single, multiple, or combined with artemether, artesunate, or praziquantel in treatment of mice infected with Schistosoma japonicum. Parasitol Res 2011, 108(2):399-406.

89. Xiao SH, Xue J, Zhang HB: Further studies on mefloquine and praziquantel alone or interaction of both drugs against Schistosoma japonicum in vitro. Parasitol Res 2012, 110(3):1239-1248.

90. Shao Y, Liu W, Wen H: [Effect of liposomal albendazole on the ultrastructure of Echinococcus granulosus cysts in mice]. Zhongguo ji sheng chong xue yu ji sheng chong bing za zhi 1999, 17(5):292-293.

91. Shuhua X, Jiqing Y, Mingjie W, Pieying J, Fanghua G, Junjie C, Wei J, Hotez P: Augmented bioavailability and cysticidal activity of albendazole reformulated in soybean emulsion in mice infected with Echinococcus granulosus or Echinococcus multilocularis. Acta tropica 2002, 82(1):77-84.

92. Chai J, Menghebat, Jiao W, Sun D, Liang B, Shi J, Fu C, Li X, Mao Y, Wang X, et al: Clinical efficacy of albendazole emulsion in treatment of 212 cases of liver cystic hydatidosis. Chin Med J (Engl) 2002, 115(12):1809-1813.

93. Chai J, Menghebat, Wei J, Deyu S, Bin L, Jincao S, Chen F, Xiong L, Yiding M, Xiuling $W$, et al: Observations on clinical efficacy of albendazole emulsion in 264 cases of hepatic cystic echinococcosis. Parasitol Int 2004, 53(1):3-10.

94. Li HT, Shan JY, Shao YM, Tuergan A, Ayifuhan A, Ran B, Wen H: [Clinical effect and safety of liposomal-albendazole and tablet-albendazole for the treatment of human cystic echinococcosis]. Zhonghua gan zang bing za zhi = Zhonghua ganzangbing zazhi 2011, 19(7):532-536.

95. Chai JJ, Menghebat, Jiao W, Sun DY, Liang B, Shi JC, Fu C, Li X, Mao YD, Wang XL, et al: [Efficacy of ablendazole emulsion in treatment of 212 patients with cystic echinococcosis]. Zhongguo ji sheng chong xue yu ji sheng chong bing za zhi 2001, 19(3):129-134.

96. Hai-tao Li KS, Ying-mei S, Wen-guang Y: Clinical observation of efficacy on liposomal albendazole on echinococcus infections in 66 cases. Endemic Dis Bull (China) 2004, 19(1):16-19.

97. Rui Rao R, Yao XC: Analysis of 102 cases adverse event of albendazole treated for echinococcosis. J Ningxia Med Univ 2009, 31(5):674-675.

98. Jevtic M, Mikic D, Arsic-Komljenovic G, Stankovic N, Ristanovic E, Sjenicic G, Janicijevic-Hudomal S: [Adverse effects of longterm, continual administration of high doses of albendazole in the treatment of echinococcal disease]. Vojnosanit Pregl 2008, 65(7):539-544.

99. Chen JH, Wang H, Chen JX, Bergquist $R$, Tanner M, Utzinger J, Zhou XN: Frontiers of parasitology research in the People's Republic of China: infection, diagnosis, protection and surveillance. Parasites Vectors 2012, 5:221.

100. McMorrow ML, Aidoo M, Kachur SP: Malaria rapid diagnostic tests in elimination settings-can they find the last parasite? Clin Microbiol Infect Publication European Socf Clin Microbiol Infect Dis 2011, 17(11):1624-1631.

101. Arora N, Banerjee AK: New targets, new hope: novel drug targets for curbing malaria. Mini Reviews Med Chem 2012, 12(3):210-226.

102. Santos $G$, Torres NV: New targets for drug discovery against malaria. PloS one 2013, 8(3):e59968.

103. Zhou BY, Chen YT, Li WG: [Research progress in antigens for the diagnosis of alveolar echinococcosis]. Zhongguo ji sheng chong xue yu $j i$ sheng chong bing za zhi 2009, 27(1):75-79.

104. Del Carpio M, Mercapide CH, Salvitti JC, Uchiumi L, Sustercic J, Panomarenko H, Moguilensky J, Herrero E, Talmon G, Volpe M, et al: Early diagnosis, treatment and follow-up of cystic echinococcosis in remote rural areas in Patagonia: impact of ultrasound training of non-specialists. PLoS neglec Trop Dise 2012, 6(1):e1444.

doi:10.1186/2049-9957-2-15

Cite this article as: Zheng et al: Research gaps for three main tropical diseases in the People's Republic of China. Infectious Diseases of poverty 2013 2:15.

\section{Submit your next manuscript to BioMed Central and take full advantage of:}

- Convenient online submission

- Thorough peer review

- No space constraints or color figure charges

- Immediate publication on acceptance

- Inclusion in PubMed, CAS, Scopus and Google Scholar

- Research which is freely available for redistribution

Submit your manuscript at www.biomedcentral.com/submit
Ciomed Central 